\title{
Violência na escola e da escola: desafios contemporâneos à Psicologia da Educação
}

\author{
Violence in school and from school: contemporary challenges to
}

Educational Psychology

\author{
Violencia en la escuela y de la escuela: desafíos contemporáneos a la \\ psicología de la educación
}

D’Aurea-Tardeli, D., Paula, F. V. de.(Org). (2009). Violência na escola e da Escola: Desafios Contemporâneos à Psicologia da Educação.

São Paulo: Editora Metodista, 139 p.

Nos últimos anos, casos de violência ocorridos nas escolas têm sido cada vez mais noticiados. Não apenas a presença cada vez recorrente, mas sobretudo a gravidade envolvida têm cada vez mais chamado a atenção da opinião pública, dos profissionais da educação e de pesquisadores.

Apesar de as discussões sobre este tema terem se intensificado no Brasil a partir dos anos 90 , ele já era notado e discutido desde os anos 80 em países como França, Inglaterra e Estados Unidos. Assim, se, por um lado, a presença destas discussões além de nossas fronteiras demonstra que este problema não é uma exclusividade de nossas escolas, mas é parte de um modo de se pensar e efetivar a educação em um contexto histórico-social determinado, por outro, também nos desafia a compreender e discutir as particularidades que assume a violência presente atualmente nas escolas brasileiras.

A escola, tal como a conhecemos hoje, é parte de uma forma específica de ordenação do mundo que se inicia com a modernidade. Suas raízes, como mostra Ariès, estão profundamente interligadas às mudanças que ocorrem a partir deste período. O modo de organizar o processo, a reconfiguração da família e dos papéis de seus membros, a redefinição e a ampliação da educação escolar foram algumas destas mudanças.

Nesta nova forma de configuração da vida social, não é apenas a exigência de conhecimentos que aumenta, mas também a necessidade de conviver em grupamentos mais amplos e diversificados. Para dar conta desta complexificação é que a escola torna-se uma instituição cada vez mais presente na vida social, ocupando um lugar central e cada vez mais longo na formação do indivíduo.
A escola, enquanto instituição social, é um espaço onde as diferenças se encontram e, portanto, local permanente de potenciais conflitos. É na escola que as diferentes formas de educação e valores familiares, culturas, etnias, religiões etc. se encontram. Neste sentido, uma importante parte da função social da escola seria ensinar a conviver em grupo, necessidade que se torna ainda mais preeminente quando se considera a necessidade de se relacionar e conviver com grupos cada vez mais amplos.

Aprender a conviver e a lidar com as diferenças seria parte do aprendizado escolar. Ensinar a lidar e, quando necessário, mediar e ensinar formas não violentas de solucionar conflitos, reforçadas ao longo de toda a história de escolarização, seriam fundamentais.

Vale ressalvar, aqui, que conflito nem sempre é sinônimo de violência, mas uma resolução inadequada de um conflito pode se transformar em um ato violento. A violência nas escolas chama atenção para a importância dada e o investimento feito neste aprendizado. Contudo, para que este aprendizado se efetive, é necessário investir numa relação não massificada, que trate profissionais da educação e alunos não como adversários, mas como sujeitos em um mesmo processo, ainda que em condições diferentes. Exige tempo e condições de trabalho que, na maioria das vezes, classes superlotadas e com relações fragmentadas pelo tempo e pelas disciplinas nem sempre contemplam.

A desigualdade (inerente à hegemônica forma moderna de se produzir a vida) é um dos aspectos que cronifica este problema. Se a escola é em si espaço de potencial conflito pelo encontro das diferenças, estas diferenças se ampliam e se tornam ainda mais acentuadas 
quanto mais amplas forem as desigualdades impostas pelas condições concretas de vida. Lembremo-nos que tanto a criação quanto a manutenção de condições acentuadamente desiguais de vida só se faz à custa de extrema violência. Contradição que não apenas se impõe à escola, mas que dela é também parte instituinte.

Por outro lado, pensar a violência nas escolas implica em discutir o que tem sido reconhecido e nomeado como violência nas escolas. Quando se aborda esta questão, percebe-se que, por detrás deste termo, diferentes representações sintetizam-se nestas palavras. Não apenas há fenômenos completamente diferentes sob um mesmo termo, como também se percebe que, muitas vezes, fenômenos que poderiam ser considerados violentos (como, por exemplo, constrangimentos públicos, brincadeiras de mau gosto, pequenas agressões físicas, coerções, extorsões etc.) são tão rotineiros que são banalizados, não chegando sequer a ser nomeados e lembrados como atos violentos.

Identificar com maior precisão o que se diz quando se fala de violência na escola é fundamental para identificar e discutir as causas, assim como para elaborar estratégias específicas de enfrentamento adequadas a cada problema. Além disso, contribuir para o reconhecimento de formas que sequer são reconhecidas como violentas pode ajudar a ampliar e requalificar o debate. A este respeito, pesquisas têm mostrado que, na maioria das vezes, por detrás das violências que chegam a ocupar as páginas de jornais, há um histórico de atos violentos que, por não terem sido reconhecidos e tratados ao longo do tempo, eclodiram de forma intensa e com potencial de dano muito mais intensificado.

Quando se trata da violência nas escolas brasileiras, outro ponto que deve ser lembrado é que os casos mais graves de violência, nos quais a vida é claramente colocada em risco, são um fenômeno predominantemente urbano. Muitos destes casos ocorrem em locais onde há presença do crime organizado, demarcando e ordenando o território e o trânsito de pessoas. Nestes contextos, a escola tem um complicador a mais, pois, algumas vezes, situações de violência que têm origens no campo extraescolar, acabam se manifestando e repercutindo no espaço escolar. Nestes casos específicos, ter de lidar com este tipo de conflito é um problema a mais para a escola. Muitas vezes abandonada nestes locais, a escola não apenas torna-se vítima como, frequentemente, passa a se exigir dela que lide com esta situação. Tarefa que, sozinha, não tem a mínima condição de fazer.

Estes diferentes aspectos aqui apenas apresentados são discutidos com competência e profundidade por diferentes autores no livro Violência na Escola e da Escola. Este livro reúne diferentes textos que, em forma de artigo, discutem o tema e esta é uma de suas maiores riquezas. Diferentes perspectivas teóricas e metodológicas são utilizadas para discutir o tema, permitindo, ao leitor, não apenas diferentes entradas para pensar um mesmo tema, mas também a possibilidade de conhecer como as diferentes teorias se posicionam e tecem uma compreensão deste problema.

Duas grandes seções compõem o livro. Na primeira seção, "Sociedade, cultura e escola: desafios e formas de resistência à violência", quatro textos discutem a produção da violência na intersecção entre sociedade, cultura e escola. Os processos de massificação, homogeneização e repressão são, de diferentes formas, discutidos nestes capítulos ao lado como possíveis formas de superação e resistência. Abre esta seção o texto de Sheila Daniela M. dos Santos que discute os aspectos semânticos e conceituais da palavra violência e suas relações com o mundo contemporâneo e a educação escolar. Sustentada pelo pensamento de Vigotski, discute como a violência, pertencendo à ordem da cultura, deixa marcas na linguagem, podendo se tornar parte de uma determinada forma de constituição da subjetividade. Discute ainda que a violência percebida na escola e através dela pode estar relacionada ao violento processo de produção da desigualdade e à negação de direitos básicos vivenciados por muitas das crianças brasileiras.

Lineu N. Kohatsu e Marian A. L. Dias discutem a impossibilidade de se compreender a violência que atualmente ocorre nas escolas desconectada da que existe na sociedade. Há, entre elas, uma relação dialética que não pode ser desconsiderada. Estes autores propõem uma estimulante discussão sobre os sentidos que podem ser atribuídos à violência na sala de aula, refletindo sobre a importância do encontro com a diferença e o diferente no processo de formação do eu. Para eles, a perda da capacidade de subjetivação faz com que o encontro com a diferença deixe de ser visto como possibilidade de experiência para passar a ser visto como ameaça. Assim, a partir de Adorno, discutem tanto a questão do preconceito como uma das formas de expressão da violência, quanto a tarefa da educação como a promoção da autorreflexão que poderia impedir a reprodução da violência.

Elizabeth dos Reis Sanada discute a violência escolar como uma resposta contemporânea ao declínio da função paterna. Para esta autora, o declínio desta função estabelece novas formas de relação e de organização do tempo e do espaço, abalando leis que anteriormente serviam como eixo norteador para uma determinada forma de existência do sujeito. Apoiando-se nas leituras psicanalítica e institucional, destaca a necessidade de responsabilização dos sujeitos e das instituições, ressaltando o papel do professor, enquanto sujeito, e da escola, como instituição, como produtores da violência e não como meros reprodutores das experiências macroestruturais. Elizabeth considera, ainda, que a violência escolar pode comportar também o estatuto de resistência contra os mecanismos disciplinares que buscam a normatização, a homogeneização e a objetificação do sujeito. Para a superação desta condição, levanta a possibilidade de resgatar o papel reflexivo da escola a fim de favorecer um posicionamento mais crítico dos elementos que são oferecidos pela contemporaneidade.

A relação que o professor estabelece com os alunos, a partir da posição central que ele ocupa na escola, é a questão abordada por Ricardo Casco. Esta relação, para este autor, pode ou não favorecer a aquisição tanto de conhecimentos como de formas de se lidar com o outro.O autor apresenta algumas interessantes reflexões sobre como 
alguns dispositivos escolares colocados na cena da relação pedagógica podem estar associados com as relações que ocorrem no interior da escola, principalmente aquelas que podem fomentar o exercício do poder e da violência entre os alunos.

A segunda seção, "Para uma escola sem violências: desafios e contribuições da psicologia da educação", é composta de cinco textos que discutem as recentes pesquisas sobre violência na escola e apresentam algumas contribuições da psicologia para a superação deste problema. Abre esta seção o texto de Alessandra Pimentel, para quem, analisar as raízes de condutas violentas nas escolas exige que se reconheça as especificidades das situações em que ela é produzida e também abrangência desta produção como componente da sociedade contemporânea. Seu texto chama a atenção para que se evitem explicações sobre a violência nas escolas meramente sociologizantes e/ou psicologizantes que tendem a focar a violência como algo exógeno à escola. A partir da perspectiva institucional, a autora propõe que a violência na escola seja também pensada no âmbito das relações intraescolares como, elas mesmas, propiciadoras de violências. Ao seu ver, a violência é constitucional e constituinte dos lugares de professor e aluno. A violência, por este prisma, é a conduta mais visível da recusa ao conjunto de valores transmitidos e representados pela instituição escolar, principalmente quando esta não responde ao universo de necessidades dos que a frequentam.

Soraia Ansara e Giseli Paim Costa observam que, apesar da violência na escola ser um tema extremamente atual e debatido, ela é ainda pouco pesquisada em suas especificidades. Para estas autoras, questões como as formas institucionais de anular as diferenças para criar a submissão e a adaptação são tão violentas quanto as reações brutais ou, até mesmo, a resistência passiva dos que subvertem esta ordem sem confrontá-la diretamente. Para a melhor compreensão deste fenômeno, propõem o aprofundamento das análises nos seguintes pontos: a) das práticas e dos processos sociais tanto na escola como na sociedade; b) do reconhecimento das condições históricas que o instituem; c) de como é definido pelos atores envolvidos; d) de como são estabelecidas as definições e normalizações das condutas violentas ou indisciplinadas pelos envolvidos nas práticas educativas; e) da análise dos mecanismos de resistência frente aos poderes instituídos.

O aprendizado para a convivência é o ponto discutido por Denise D'Aurea-Tardeli. Para esta autora, as pesquisas têm mostrado que a escola tem falhado no ensino da boa convivência. Para estabelecer propostas educacionais democráticas que se traduzam em currículos que valorizem a boa convivência, a justiça e a equidade, a autora discute e argumenta sobre a necessidade de que questões relacionadas ao desenvolvimento psicológico e da moralidade sejam conhecidas e levadas em conta tanto pelo sistema educacional como pela própria escola.

Fraulein Vidigal de Paula discute o quanto a violência obstaculiza o papel da escola em promover o desenvolvimento humano. Contudo, não é simples combater a violência neste ambiente, pois atravessam as mais diferentes esferas de relações num jogo complexo de variáveis. A autora explora e discute algumas variáveis (formas como a violência se manifesta, atores envolvidos e fatores ambientais, psicológicos e culturais) que podem contribuir para desencadear a violência e, posteriormente, apresenta alguns resultados de pesquisas brasileiras que poderiam ajudar no enfrentamento da violência escolar.

Maria Isabel da Silva Leme fecha não apenas esta seção, mas o livro, mostrando como, mesmo a partir de perspectivas teóricas diferentes, é possível estabelecer algum diálogo ao se identificar elementos em comum. Um destes elementos é o próprio conceito de violência que, apesar da polissemia, não foi, por nenhum dos autores, naturalizada ou discutida como tendência herdada, nem associada à irracionalidade que caracteriza a agressividade em outras espécies da filogênese. A violência, como aponta a autora, deve ser pensada em uma perspectiva dinâmica, como algo inerente ao processo civilizatório de dominação da natureza, que, como potência das transformações, é passível de emergir modificando as relações. Portanto, para se compreender a violência, é necessário uma ação racional, que articule meios e fins. Outro ponto comum encontrado pela autora é o de que todos os textos apontam a violência escolar como um fenômeno de diferentes níveis e com múltiplas determinações. Portanto, a análise deste fenômeno não pode ser feita nem de maneira simplista e reducionista, o que dificulta discriminar as suas diferentes formas de ocorrência e manifestações, nem a partir de explicações totalizadoras, que impedem considerar como a escola institui e controla as relações que ocorrem em seu interior. Por fim, propõe a autora que o primeiro passo para o enfrentamento da violência na escola deveria ser o abandono das idealizações (seja do passado, da infância ou das relações educativas) para que um segundo passo seja possível, o da democratização das relações entre os membros da comunidade escolar. Democratizar as relações implica em reconhecer e respeitar as diferenças, ao mesmo tempo em que se garanta um tratamento imparcial e igualitário a todos em relação às regras que, como bem enfatiza a autora, devem ser claras, acessíveis e fruto de discussões coletivas na escola.

Sem a pretensão de sê-lo, este livro é uma obra de referência sobre tolerância e convivência ao discutir com tanta pluralidade um mesmo tema. A pluralidade aqui encontrada é nele fundamental para analisar a violência na e da escola: um fenômeno lábil, complexo e multideterminado.

Todavia, a pluralidade de visões e análises aqui apresentadas frustrará quem quiserencontrar porparte destes diferentes autores respostas prontas e acabadas. Mais do que respostas, os textos, em seu conjunto, oferecem pistas para reflexão. Pistas estas que ajudam todos os envolvidos com a educação escolar a pensar velhos e novos problemas de forma diferente e não apenas nas diferenças, mas, a partir das diferenças, construir os próprios caminhos. 
